\section{Implementing Sustainable Practices on Campus through Student Independent Study}

\author{
Susan S. Barton ${ }^{1,3}$, Rebecca S. Pineo ${ }^{1}$, and Leslie Carter $^{2}$
}

AdDITIONAL INDEX WORDs. landscape, sustainability, project, interpretive signage

Summary. Two students at the University of Delaware participated in independent study projects that helped the University of Delaware campus progress in their efforts to become a sustainable campus. Student projects included a volunteer organization for invasive plant removal, design of a wildlife habitat garden, development of an interpretive signage policy, coordination of publicity, development of interpretive signs, authoring fact sheets, and creation of a sustainable landscapes website. Students benefited from faculty mentoring, collaboration with other university and agency personnel, and real world project coordination. Both students are currently enrolled in graduate programs that will further develop the skills they learned in their independent study projects.

$\mathrm{U}$ niversity campuses provide an excellent opportunity to research and demonstrate sustainable landscape practices. Most campuses include significant land resources, a variety of building types, and diverse plantings. University campuses must be managed with attention to aesthetics, economics, and environmental health. An attractive campus is an important recruiting tool and an important contributor to a desirable student experience (Dober, 2000). Campus grounds divisions have strict budgets to follow and are managed with an attention to issues such as invasive plant control, storm water management, and biodiversity.

At the University of Delaware (UD), the Division of Facilities includes "grounds services" and "planning and construction." Both departments have been charged with implementing sustainable practices throughout their activities.

In addition to required course work, students at UD have a number of opportunities to complete special projects and undergraduate research. A variety of levels of commitment and structure are available from independent study courses, to senior theses, to degrees with distinction.

The most common option for students participating in academic year research is to enroll in an independent

${ }^{1}$ University of Delaware, Cooperative Extension Service, Townsend Hall, 531 South College Avenue, Newark, DE 19717

${ }^{2}$ University of Pennsylvania, Landscape Architecture, Department of Landscape Architecture and Regional Planning, Meyerson Hall, 210 S 34th Street, Philadelphia, PA 19104-3899

${ }^{3}$ Corresponding author. E-mail: sbarton@udel.edu. study course. This option allows students to receive credit for completing research; however, it also comes with a time commitment. Students and their faculty advisor discuss the time commitment that works best for the student, faculty advisor, and project ( 1 credit independent study $=3-5 \mathrm{~h} /$ week, 2 credits $=6-9 \mathrm{~h} /$ week, 3 credits $=10-12 \mathrm{~h} /$ week $)$ (Wolfgang, 2009).

A senior thesis is a paper that highly motivated senior undergraduates may write to present results of a major, independent research or creative project. Unlike most term projects, papers, and laboratory reports written in undergraduate courses, a senior thesis addresses questions or issues for which no known or generally accepted answers exist.

A degree with distinction can be earned when students conduct original research or creative work, write a senior thesis, enroll in UNIV401 and 402 , and successfully defend the work before a committee of university facin a baccalaureate degree title.

Students who complete an independent project at any level (independent study course, senior thesis, or degree with distinction) have the opportunity to explore their aptitude for research, gain real world experience, learn collaborative skills, and, in many cases, oversee the implementation of their project. Independent study experiences provide students with the opportunity to learn how to gain knowledge rather than simply providing the knowledge itself (Harvey and Mason, 1996). Students develop ulty. The term "distinction" is included close relationships with a faculty member, as well as with the greater university's community of scholars through close contact with committee members, other interested faculty, graduate and postdoctoral students, and fellow undergraduate researchers. Students who complete a senior thesis or degree with distinction demonstrate to graduate schools, fellowship committees, and employers their intellectual achievement and sophistication as well as initiative and self discipline. As a capstone of the undergraduate experience, a senior thesis provides the opportunity to draw upon everything the student has learned in his or her college experience and make a significant contribution.

A number of events converged at UD to provide opportunities for two students to complete independent study projects that built on one another and resulted in the implementation of a new wildlife habitat landscape on campus complete with interpretive signage and the construction of a sustainable landscape website (Pineo, 2009).

In 2006, Leslie Carter, an honors student double majoring in Wildlife Conservation and Landscape Horticulture embarked on a senior thesis that involved three components: invasive plant control, wildlife habitat garden design, and interpretive signage. At that time, the UD visitor center parking lot was surrounded by a large hedge of burning bush (Euonymus alatus), an invasive plant listed on the Delaware Invasive Species Council restricted and invasive plant list (Delaware Invasive Species Council, 2009). Leslie spent the previous summer working $2 \mathrm{~d}$ each week with Delaware Natural Resources and Environmental Control parks and recreation team of summer employees who removed burning bush from the White Clay Creek State Park (WCCSP). Because one section of the WCCSP is adjacent to the UD campus, removal of this prominent burning bush hedge was significant from a symbolic and real seed contribution perspective. Leslie received permission from grounds services to organize a volunteer task force and physically remove all 27 mature burning bush shrubs (Fig. 1). She developed a poster to explain the project, which was exhibited at the UD visitor center, and the event received coverage in the Wilmington News Journal. 


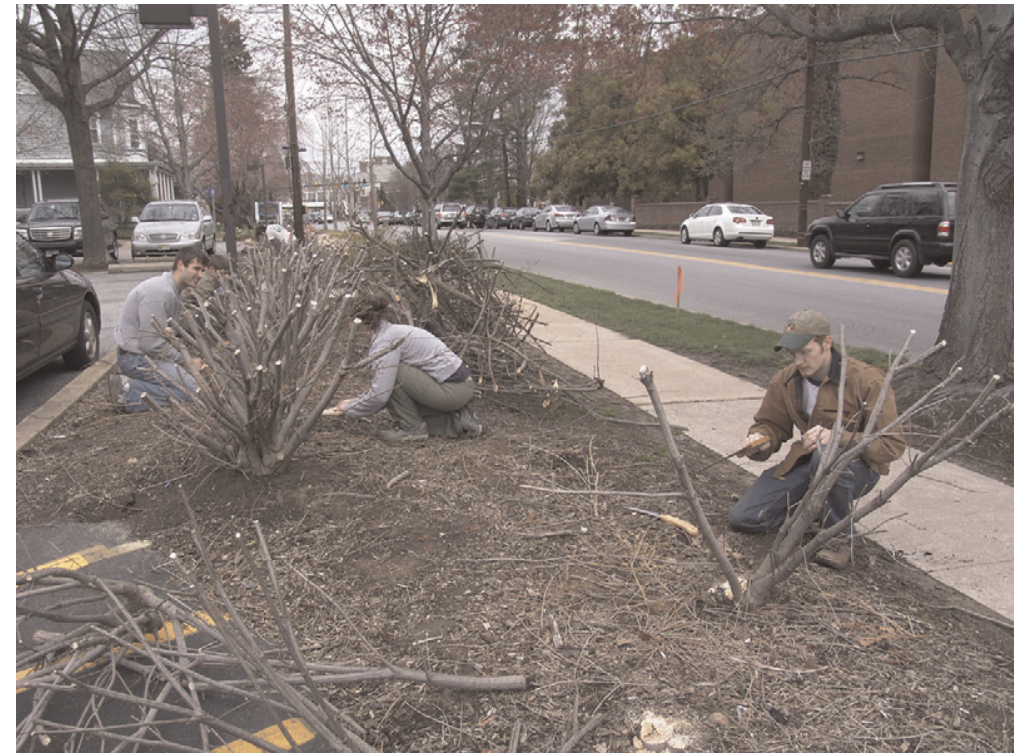

Fig. 1. Leslie Carter as part of her senior thesis project received permission from grounds services to organize a volunteer task force and physically remove all 27 mature burning bush shrubs from the University of Delaware visitor center parking lot.

Because the UD was in the process of designing a new visitor center, Leslie was able to develop a landscape design for the facility that incorporated principles of wildlife habitat (to include diversity, to provide four basic needs, to use native species, to avoid or reduce the use of chemicals, and to plan for succession) (Tufts and Loewer, 1995). Leslie worked with landscape planner, Tom Taylor, to create a design that would incorporate a variety of niches to support wildlife, while maintaining enough simplicity to satisfy the desired aesthetic appeal and fit the UD's landscape style. Leslie's design and plant list were incorporated into the project implemented by Tom Taylor when the garden was installed in Summer 2008.

A large number of students and parents visit university campuses each year. This visitation provides an opportunity to provide not only education about the university and its campus, but also address sustainable landscape education. After installing a garden to enhance wildlife habitat, the UD chose to educate visitors about the principles included in the garden and teach them how to implement those principles in their own landscapes. What better place than a visitor center landscape to educate as many people as possible? The task of creating interpretive signage was more complicated than it might have been because the UD did not have any written policies for interpretive signage. Leslie's project became researching and developing an interpretive signage protocol for the university. Leslie researched interpretive signage literature for public gardens and interviewed interpretation experts at three local public gardens (Longwood Gardens, Tyler Arboretum, and Winterthur Museum and Gardens). She worked with a design manager in planning and construction to ensure acceptability of the protocol throughout campus.

Leslie Carter graduated from the UD in 2007. She spent 1 year as the education intern at Longwood Gardens and is now a Masters of Landscape Architecture student at the University of Pennsylvania. Leslie regards her undergraduate research at UD as an extremely valuable part of her college career. "I learned a lot about the process of developing and working through a research project, as well as several aspects of sustainable landscapes. The skills I gained from this project, such as how to break a large task into smaller, more achievable goals, have been helpful in multiple endeavors I have since undertaken. It was also a great opportunity to work closely with a faculty member and develop the fundamentals of a strong professional network that has proved to be advantageous."
In 2008 , the University of Delaware Botanic Gardens (UDBG) Executive Committee established a subcommittee for extension and research. The subcommittee began to work on the implementation of sustainable practices and raising the awareness of existing sustainable practices on the UD campus. As a starting point, the UDBG green subcommittee (UDBGGS) developed a white paper on sustainable landscape practices for Delaware. The primary reference for this white paper was the Sustainable Sites Initiative (SSI) preliminary report, which was published 1 Nov. 2007 and is available on the SSI website (SSI, 2007).

In Fall 2008, Rebecca Pineo, a student intern at UDBG, decided to do an independent study project to interpret the sustainable landscape practices implemented at the visitor center landscape for the public. Using the information summarized in the white paper, Rebecca helped her faculty advisor develop the text and select images for a large interpretive sign to be placed near the entrance of the visitor center. A graphic artist was hired by the College of Agriculture and Natural Resources (CANR) to design the sign. The design process included many revisions in format, photographs, and text. It required negotiation with UDBGGS members to develop accurate text wording to achieve the proper educational goals. The sign was approved in Jan. 2009, produced in Feb. 2009, and installed 15 Mar. 2009.

Simultaneous to the development of the visitor center interpretive sign, Rebecca developed a sustainable landscapes website, which is now housed on the UDBG website (UDBG, 2008). The URL for the website is printed on the visitor center sustainable landscape sign. Rebecca used a structure outlined by the SSIsoils, hydrology, vegetation, materials, and human wellness. The home page includes a definition of sustainable landscape, the benefits of sustainable landscapes, and an icon that provides a link to individual pages on soils, hydrology, vegetation, materials, and human wellness. Each individual page includes two to seven bulleted sustainable practices with links to fact sheets that provide more information on the practice. Rebecca used existing resources whenever possible and included 13 links to Delaware extension 
fact sheets and two regional publications. Rebecca also wrote 15 new fact sheets providing detailed information on 15 sustainable landscape practices. Information for fact sheets was gathered from web resources, books, journal articles, industry lectures, and in a few cases, class notes. All fact sheets were edited by the faculty advisor. Soon after it was launched, the sustainable landscapes website drew national attention from the U.S. Botanic Garden (USBG). Ray Mims from the USBG was thrilled with the use of the SSI information and suggested that the UDBG sustainable landscapes site might provide a template for use by other public gardens to interpret this information for homeowners.

Finally, Rebecca finished her independent study project by developing and locating six small signs that are distributed throughout the visitor center landscape to provide more detailed information on plant adaptability, the use of compost, plants as groundcovers, managing water with rain gardens, attracting wildlife, and the benefits associated with engaging people in the landscape (Fig. 2). UD recently held its first Forum and Reunion Weekend on 5-6 June, and the CANR featured sustainable landscaping in its college showcase by touring interested attendees through the new visitor center's sustainable landscape complete with interpretive signs.
Rebecca Pineo was accepted into the Longwood Graduate Program in Public Horticulture and began her master's program in July 2009. Rebecca reflects on her experiences and believes "'study' is an understatement-independent studies are so much more than an academic exercise. For me, the real end product was not a grade, but the satisfaction of contributing to the university community, the sustainable landscapes movement, and the field of public horticulture in general. Not to mention the projects look great on my résumé!”

She goes on to say "Actually collaborating with Dr. Barton-not just being graded by her-was in itself incredibly enriching. Her expertise, guidance, and encouragement as a mentor were central to my positive learning experience. I think a good fit between the interests of the student and the faculty advisor really is key to a successful independent study."

These two students accomplished significant projects that each moved the UD forward in its effort to conduct and promote sustainable landscaping on campus. Possibly, equally as important, the UD taught two students how to work within a complicated system, collaborate with colleagues, and develop tools that will be used to educate thousands of people in the future.

Independent study experiences are most useful when there is a close

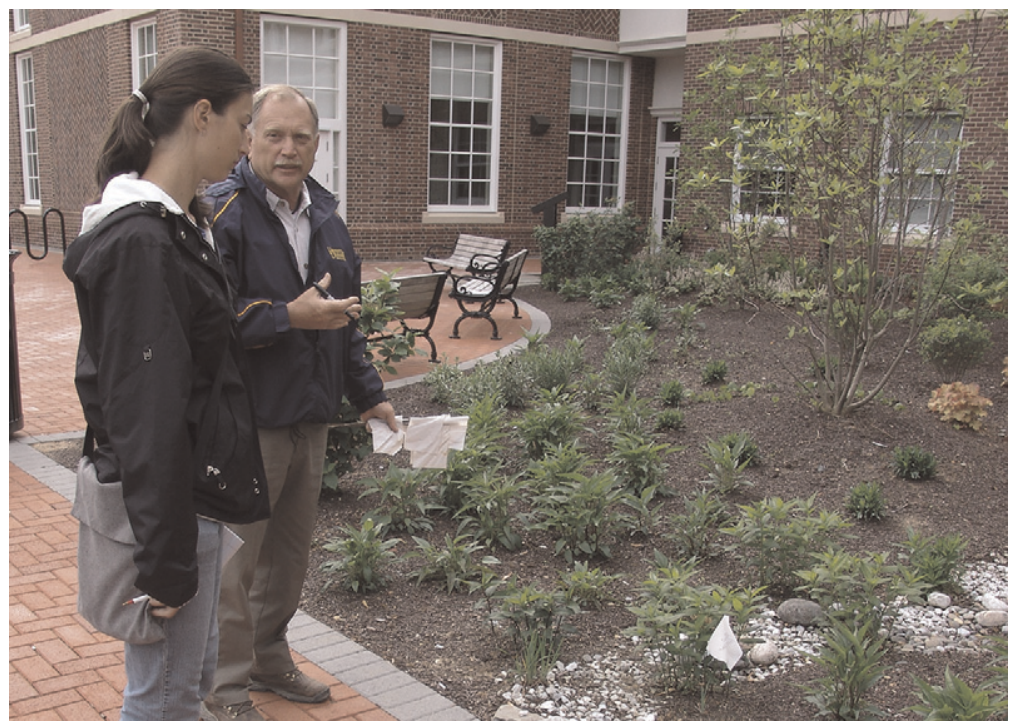

Fig. 2. As part of her independent study project, Rebecca Pineo worked with landscape planner Tom Taylor to locate six small signs in the visitor center landscape to provide more detailed information on plant adaptability, use of compost, plants as groundcovers, managing water with rain gardens, attracting wildlife, and the benefits associated with engaging people in the landscape.

relationship with the faculty advisor. The project should interest the student and the faculty advisor, so they are equally engaged in the process. Faculty advice on resources and contact people can pave the way for student success. Faculty editing throughout the process will enrich student learning.

It is also important for students to work with other UD staff and outside agencies. This develops collaborative skills and shows students how most projects are accomplished in the business or nonprofit world. In both cases, students also worked with outside agencies to get newspaper coverage for the invasive removal event or to design and produce interpretive signs.

Student research is critical to the success of an independent study project. No one knows everything required to complete a project at the onset. Learning where to look and how to find relevant information is a key skill that independent study projects can help develop. While not always possible for students to see the implementation of their independent study project, when that happens, it makes the learning experience even more valuable, as there is a tangible sign of the student's work. These two students will be able to visit the visitor center landscape and see visitors learning from their efforts. The experience of independent study, which requires considerable flexibility and adaptability to deal with unforeseen circumstances and to strive toward a result, is ideal training for the types of skills desired by most employers (Harvey and Mason, 1996).

Finally, sharing work with other colleagues at national meetings or in national publications can complete the learning loop for students.

\section{Literature cited}

Delaware Invasive Species Council. 2009. Delaware Invasive Species Council restricted and invasive plant list. 15 June 2009. <http://www.delawareinvasives. net/invasive_plants $>$.

Dober, R.P. 2000. Campus landscape. Wiley, Hoboken, NJ.

Harvey, L. and S. Mason. 1996. A quality graduate. Chapter 2. In: J. Tait and P. Knight (eds.). The management of independent learning. Korgan Page in association with Staff and Educational Development Association, London. 


\section{Sustainability and Horticultural Education}

7 Feb. 2010. <http://books.google.com/ books?hl=en\&lr=\&id=Fkk9AAAAIAAJ\& $\mathrm{oi}=$ fnd \&pg $=$ PR7 \&dq $=$ tait + and + knight + education \& ots =intq MrrPzn\&sig= rBvO8UMzZoNDhaqp2C2lg-Qp7EQ\#v= onepage \&q=tait $\% 20$ and $\% 20$ knight $\% 20$ education $\& \mathrm{f}=$ false $>$.

Pineo, R. 2009. University of Delaware Botanic Gardens sustainable landscapes.
15 June 2009. <http://ag.udel.edu/ $\mathrm{udbg} / \mathrm{sl} />$.

Sustainable Sites Initiative (SSI). 2007. The Sustainable Sites Initiative, preliminary report. 9 May 2008. <http://www. sustainablesites.org/>.

Tufts, C. and P. Loewer. 1995. Gardening for wildlife. National Wildlife Federation, Rodale Press, Emmaus, PA.
University of Delaware Botanic Gardens (UDBG). 2008. UDBG website. 15 June 2009. <http://ag.udel.edu/udbg/sl>.

Wolfgang, G. 2009. UD undergraduate research program. 15 June 2009. <http://urp.udel.edu/abroad/OtherUD opportunities.aspx $>$ 